\title{
||||||||||||||||||||||||||||||||||||||||||||||||||||||||||||||||||||.
}

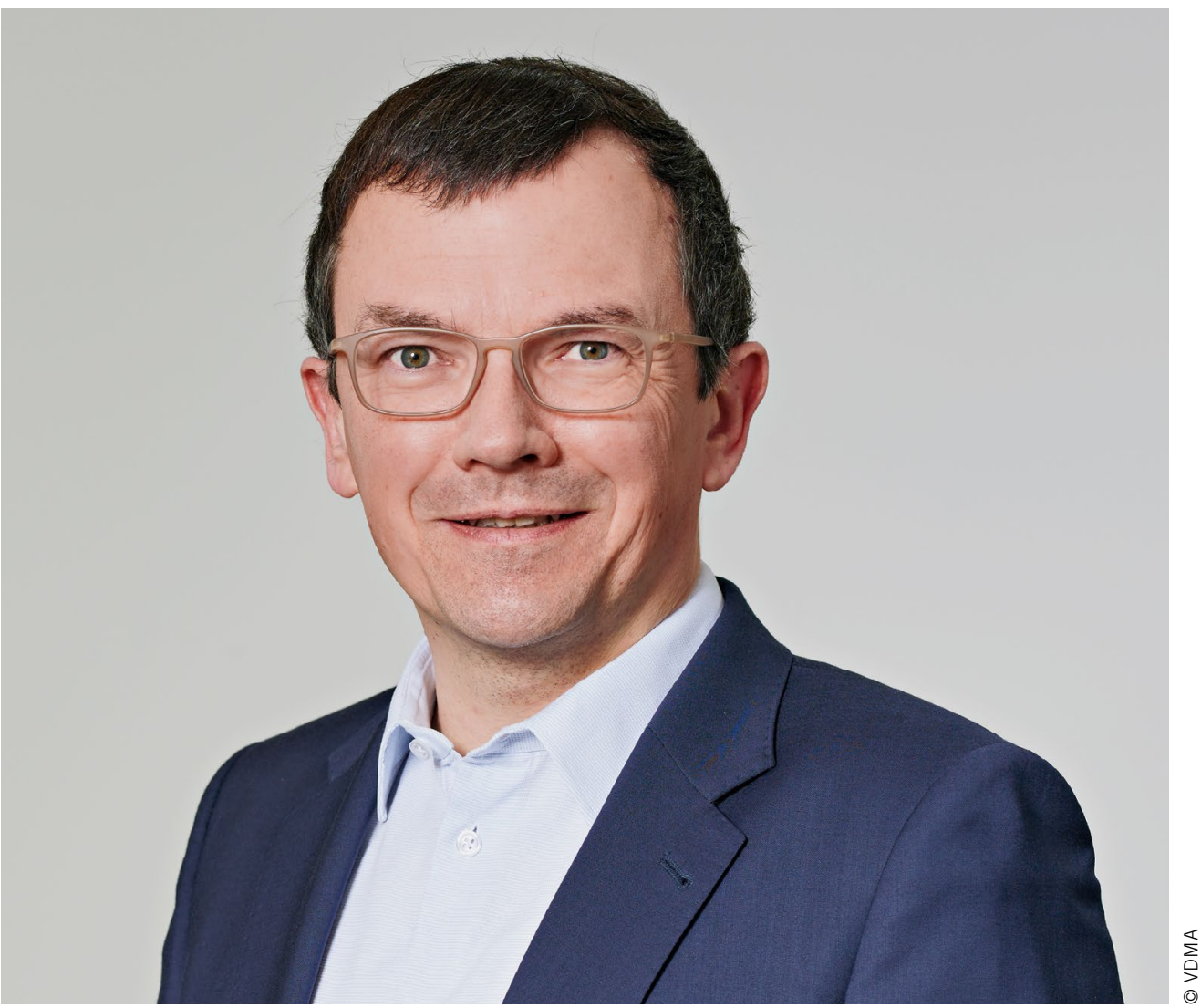

Peter Müller-Baum

Managing Director VDMA Engines and Systems, Power-to-X for Applications and Secretary General CIMAC

\section{Off the High Horse}

Sometimes I wonder how today's social media with their usual simplifications would react to the change in street scenes from horse-drawn carriages to automobiles, which took place about 100 years ago: Would there also be the faction that are not becoming tired of pointing out that there won't be enough gas stations to permanently supply all automobiles with fuel? Or those who urgently want to ban horsedrawn carriages because automobiles are much more efficient?

Yes, maybe this is a rather lousy comparison - but this constant "either/or" debate seems similarly absurd to me. Isn't it obvious that in the long run - meaning in a defossilized world battery electric vehicles can play out their advantages, namely efficiency and, yes, later, also low cost, in various applications? And that there are nevertheless areas in which not only physics, but also economic arguments speak against relying solely on one technology? Examples are aviation and shipping, in parts heavy duty vehicles and mobile machinery, and the huge existing car fleet worldwide. In some areas of the world by the way, you still see horse carriages riding down the streets.

For the large engine industry, these questions can be answered quite simply and unambiguously (and for the most part without much of a discussion). The problem here, however, is that such a massive change in mobility, as we can foresee at the horizon right now, will of course have tremendous effects on the entire value chains, including the academic world. If no more internal combustion engines are built for road use in Europe, will the expertise, the large engine industry relies on, still be available here? What will the supplier industry look like in the future? How will the world of research evolve?

All these questions are complex and certainly cannot be answered here, especially since the interactions with future power systems and world trade flows have not even been touched. My hope, however, would be that we manage to objectify this discussion. Because, while the incipient change is, in my opinion (and rightly so), unstoppable, the associated challenges can only be solved together in such a way that they are not accompanied by serious losses of prosperity. A debate that is as uninfluenced by polemics as possible would be necessary for the further development of practical and acceptable solutions worldwide. 